\title{
PORTAIS INSTITUCIONAIS NA WEB: ANÁLISE DE ANÚNCIOS PUBLICITÁRIOS NO ECOSSISTEMA MIDIÁTICO
}

EUGENIA MARIANO DA ROCHA BARICHELLO

UNIVERSIDADE FEDERAL DE SANTA MARIA SANTA MARIA, RIO GRANDE DO SUL, BRASIL EUGENIABARICHELLO@GMAIL.COM

TAÍS STEFFENELLO GHISLENI UNIVERSIDADE FEDERAL DE SANTA MARIA SANTA MARIA, RIO GRANDE DO SUL, BRASIL TAISGHISLENI@YAHOO.COM.BR

HTTP://DX.DOI.ORG/10.5902/2316882X25718 


\section{PORTAIS INSTITUCIONAIS NA WEB: ANÁLISE DE ANÚNCIOS PU- BLICITÁRIOS NO ECOSSISTEMA MIDIÁTICO}

Resumo: A tese analisa as mudanças dos anúncios publicitários em sites institucionais no cenário da nova ecologia midiática. A cartografia é utilizada como estratégia metodológica, pois permite acompanhar os movimentos de transformação da paisagem confirmando que a publicidade está construindo o seu espaço na ambiência digital, o espaço dedicado aos anúncios aumentou e isso revela uma adesão maior dos anunciantes à publicidade veiculada na web.

Palavras-chave: Estratégias Comunicacionais, Publicidade digital, Ecologia midiática, Cartografia na Comunicação, Anúncios publicitários.

\section{PORTALES WEB INSTITUCIONALES: ANÁLISIS DE PUBLICIDAD EN EL ECOSISTEMA DE MEDIOS}

Resumen: La tesis analiza los cambios de comerciales en sitios institucionales en el escenario de la ecología de los nuevos medios. La cartografía se utiliza como estrategia metodológica, ya que permite seguir los movimientos de transformación del paisaje confirmando que la publicidad está construyendo su espacio en el entorno digital, el espacio dedicado a los anuncios ha aumentado y esto revela una mayor adhesión de los anunciantes al anuncio publicado en la web.

Palabras Clave: Estrategias Comunicativas, Publicidad Digital, Ecología de los Medios, Cartografía en Comunicación, comerciales.

\section{INSTITUCIONAL WEB PORTALS: ANALYSIS OF ADVERTISEMENTS IN THE MEDIA ECOSYSTEM}

Abstract: The thesis analyzes the changes of commercials in institutional sites in the scenario of the new media ecology. Cartography is used as a methodological strategy, because it allows to follow the movements of transformation of the landscape confirming that advertising is building its space in the digital environment, the space dedicated to the ads has increased and this reveals a greater adhesion of the advertisers to the advertisement served on the web.

Keywords: Communicative Strategies, Digital Advertising, Media Ecology, Cartography in Communication, commercials. 


\section{INTRODUÇÃO}

A configuração da publicidade no ecossistema da internet passa, com certeza, pelas formas de interação, e a digitalização proporciona novas possibilidades interativas, redefinindo as tradicionais formas de interação praticadas na publicidade tradicional.

Tendo em vista o entendimento da importância de as estratégias comunicacionais adaptarem-se à ambiência midiatizada, o objeto de estudo desta tese são os portais institucionais (Brastemp, Coca-Cola, Colgate, Fiat, Itaú, McDonalds, Samsung, Skol, Tim e Visa), com foco nos anúncios neles publicados e utilizados como estratégia comunicacional no período que inclui o início comercial da internet até a atual ecologia midiática. A ênfase encontra-se especialmente na trajetória de uso das possibilidades trazidas pelas tecnologias da informação e comunicação. Trata-se, portanto, de uma análise de objeto empírico que dirige a sua reflexão às práticas publicitárias institucionais, atentando às reconfigurações que nelas operam as novas tecnologias a serviço da comunicação. Como a publicidade não ocorre em um vácuo social, a pesquisa não perde de vista a conjuntura cultural em que se dá a visibilidade das instituições, agora sob o impacto de novos aparatos tecnológicos.

O mercado publicitário tem passado por diversas alterações e inovações possibilitadas, dentre outras causas, por novos meios e formatos de veiculação de mensagens. Essas novas possibilidades crescem continuamente e abrem diversas opções aos anunciantes e às campanhas publicitárias, que podem se comunicar com o público de forma inovadora e interativa.

Com o advento das tecnologias da informação, os meios de comunicação começaram a migrar dos meios tradicionais de comunicação para os meios digitais, e é pressuposto que a publicidade existe associada ao desenvolvimento desses meios (jornais, rádio e televisão). Com a evolução em curso, a publicidade também passou por transformações para a disseminação das suas mensagens. No entanto, consideramos a hipótese de que as práticas publicitárias não se alteraram na sua essência, pois seguem com sua função como técnica de comunicação que visa persuadir as audiências dos diferentes suportes de comunicação e informação, por meio da veiculação de mensagens.

As práticas são organizadas por um saber coletivo que impõe regras e

Rev.Cad.Comun. Santa Maria, v.21, n.2, art 6, p. 119 de 125, maio/ago.2017 
normas de produção para o que é considerado uma publicidade adequada. Esse saber é modificado de acordo com o contexto e a delimitação do campo de atuação. Assim, o controle do campo dos anúncios para determinado grupo é o que se institucionaliza como prática publicitária. O contexto atual sinaliza um modus operandi que rompe com as práticas publicitárias das instituições nas últimas décadas e faz com que as organizações procurem adaptar seus anúncios às novas ambiências para sobreviver, já que, como pontua Scolari (2012, online), a "chegada de novas espécies de mídia está transformando o ecossistema".

\section{OBJETIVOS}

O nosso objetivo geral é analisar as mudanças dos anúncios publicitários nos sites institucionais de marcas no cenário da nova ecologia midiática. Para alcançá-lo, estabelecemos como objetivos específicos: mapear a evolução dos formatos de anúncios publicitários utilizados nas homepages (páginas iniciais) dos sites institucionais das marcas em análise desde a web 1.0 até o paradigma atual; observar as mudanças nos portais a partir da forma genérica como os conteúdos são colocados, das práticas e do tipo de publicidade utilizado em cada momento; listar os formatos dos anúncios publicitários conforme apresentados ao utilizador, seguindo a classificação de Sebastião (2011) e DoubleClick (2016, online); classificar os portais institucionais das marcas selecionadas em quatro momentos principais: transposição dos meios tradicionais para o suporte online; tentativa de criar para o meio digital; interatividade com os usuários; e transposição da ambiência web para a ambiência mobile; verificar se a homepage tem a capacidade de interagir com o usuário ou não e como isso acontece com base nos tipos de interatividade propostos por McMillan (2002); observar a interatividade proporcionada pelos anúncios e os dispositivos presentes nessa prática; descrever a evolução de anúncios digitais em termos de interatividade destacando os dispositivos interacionais do fenômeno comunicacional aplicados à publicidade digital; e ainda, elaborar uma matriz cartográfica para a publicidade online nos portais das marcas selecionadas sob a ótica da teoria ecológica. 


\section{CONSIDERAÇÕES METOdOLÓGICAS}

A cartografia surgiu como opção metodológica, pois permite acompanhar os movimentos de transformação da paisagem. A proposta é apresentar um desenho que represente como a publicidade está construindo o seu espaço na plataforma digital, mais especificamente na web e o corpus da pesquisa inclui portais selecionados a partir dos quesitos: a) estarem registrados no órgão federal Registro.br'; b) estarem presentes na internet, com versões brasileiras e o mesmo endereço, há mais de quinze anos; c) estarem citados entre as marcas nas pesquisas Top Of Mind desde 2007; d) marcas mais lembradas na pesquisa Top of Mind Internet $2014^{2}$.

Para acessar os portais anteriores, foi utilizada a ferramenta disponível na web denominada Internet Wayback Machine (IAWM), que constitui um banco de dados digital3 , que funciona como um museu digital, já que arquiva páginas da web desde 1996. Este site permite visualizar como o design e a usabilidade dos sites evoluiu ao longo do tempo e é possível conferir tendências que marcaram épocas, especialmente na publicidade digital.

\section{PRINCIPAIS RESULTADOS}

O estudo dos dez portais mostrou uma transformação nas práticas publicitárias desde o início da internet comercial no Brasil até 2016. Grande parte da transformação foi impulsionada pela evolução das possibilidades tecnológicas, mas estas só puderam alterar o mercado, pois sempre estiveram aliadas ao comportamento do consumidor, que também foi se adaptando.

No ecossistema midiático digital, ocorrem transformações estruturais na publicidade e em suas práticas e é possível perceber que a publicidade tradicional está migrando para a internet, pois conforme aumenta o uso da rede pelos consumidores, desloca-se também o investimento das em-

\footnotetext{
1 O registro de domínios, nas categorias sob o .br, está disponível para pessoas físicas (CPF) e jurídicas (CNPJ) legalmente representadas ou estabelecidas no Brasil com cadastro regular junto ao Ministério da Fazenda. Disponível em: <http://registro.br/dominio/regras.html> Acesso em 12 nov. 2013.

2 É a última pesquisa cujos dados foram divulgados.

3 A ferramenta mapeia o número de vezes que os sites foram rastreados pela Wayback Machine, não quantas vezes o local foi realmente atualizado.
}

Rev.Cad.Comun. Santa Maria, v.21, n.2, art 6, p. 121 de 125, maio/ago.2017 
CADERNOS DE COMUNICAÇÃO

UNIVERSIDADE FEDERAL DE SANTA MARIA

presas para esse meio, já que o custo da publicidade na ambiência digital é menor, e a flexibilidade é maior em relação aos outros meios de comunicação. As práticas publicitárias mudam em função de transformações envolvendo o contexto, os anunciantes e o público de forma geral, e a matriz que a tese originou pode ajudar a mapear essas transformações.

\begin{tabular}{|c|c|c|}
\hline \multicolumn{3}{|c|}{ Marca } \\
\hline \multicolumn{3}{|c|}{ Período } \\
\hline \multirow{3}{*}{\multicolumn{3}{|c|}{$\begin{array}{l}\text { Web } 1.0 \text { - consumo de informações (unidirecional) } \\
\text { Web } 2.0 \text { - participação (Mídias sociais) (bidirecional) } \\
\text { Web } 3.0 \text { - aperfeiçoamento da tecnologia (comunicação colaborativa) }\end{array}$}} \\
\hline & & \\
\hline & & \\
\hline \multirow{4}{*}{ Critérios pré-definidos } & \multicolumn{2}{|c|}{ Transposição dos meios tradicionais } \\
\hline & \multicolumn{2}{|c|}{ Tentativa de criar para o meio digital } \\
\hline & \multicolumn{2}{|c|}{ Interação com os usuários } \\
\hline & \multicolumn{2}{|l|}{ Transição da web para mobile } \\
\hline \multirow{5}{*}{ Tipo de publicidade $^{4}$} & Publicidade de produto & Publicidade comparativa \\
\hline & Publicidade de serviços & Publicidade cooperativa \\
\hline & $\begin{array}{l}\text { Publicidade genérica (ou de } \\
\text { commodities) }\end{array}$ & Publicidade de promoção \\
\hline & Publicidade de varejo & Publicidade legal \\
\hline & Publicidade de classificados & Não se aplica \\
\hline \multirow{8}{*}{ Tarefa da publicidade } & \multicolumn{2}{|c|}{ Divulgação da marca (de produto ou serviço) ou empresa } \\
\hline & \multicolumn{2}{|c|}{ Promoção da marca ou empresa para seus consumidores } \\
\hline & \multicolumn{2}{|c|}{ Criação de mercado para a marca ou empresa } \\
\hline & \multicolumn{2}{|c|}{ Expansão do mercado } \\
\hline & \multicolumn{2}{|l|}{ Correção do mercado } \\
\hline & \multicolumn{2}{|l|}{ Educação do mercado } \\
\hline & \multicolumn{2}{|l|}{ Consolidação do mercado } \\
\hline & \multicolumn{2}{|l|}{ Manutenção do mercado } \\
\hline \multirow{4}{*}{ Formatos ${ }^{2}$} & \multicolumn{2}{|l|}{ Anúncios de pesquisa } \\
\hline & \multicolumn{2}{|l|}{ Anúncios de exibição $\rightarrow$ banner } \\
\hline & \multicolumn{2}{|l|}{ Classificados } \\
\hline & \multicolumn{2}{|l|}{ Não se aplica } \\
\hline \multirow{5}{*}{$\begin{array}{l}\text { Tecnologia } \\
\text { predominante que foi } \\
\text { utilizada }\end{array}$} & \multicolumn{2}{|l|}{ Imagem estática } \\
\hline & \multicolumn{2}{|l|}{ Gif } \\
\hline & \multicolumn{2}{|l|}{ Flash } \\
\hline & \multicolumn{2}{|l|}{ JavaScript } \\
\hline & HTML5 & \\
\hline & Utilizador para utilizador & \\
\hline${ }_{6}$ Tipos de interatividade & Utilizador para documentos & \\
\hline & Utilizador para sistema & \\
\hline & Banner ou AdServers; & \\
\hline Interativịdade em & Rich Media; & \\
\hline anúncios ${ }^{7}$ & Widget ou Rich Media Advar & \\
\hline & Não se aplica & \\
\hline
\end{tabular}

$4 \quad$ Os tipos e as tarefas da publicidade estão baseados em Pinho (2001).

5 Os formatos foram construídos com base em Sebastião (2011).

6 Os tipos de interatividade seguem a classificação indicada por McMillan (2002).

7 A interatividade em anúncios está construída com base em Fernandes (2011) e Duarte (2011).

Rev.Cad.Comun. Santa Maria, v.21, n.2, art 6, p. 122 de 125, maio/ago. 2017 


\section{CONCLUSÕES}

Observamos mudanças evidentes nos formatos dos anúncios publicitários e um dos aspectos relevantes é o espaço dedicado aos anúncios, que aumentou de forma considerável ao longo dos anos, fato que revela uma adesão maior dos anunciantes à publicidade veiculada na web.

Já existem diversas formas de se fazer publicidade na web que incluem desde simples banners até páginas completas e os formatos da publicidade digital se alteram em curtos espaços de tempo, acompanhando as transformações das tecnologias e do próprio meio. É necessária uma análise de mercado para saber qual o tipo de publicidade é mais indicado para o que se deseja alcançar, já que a internet é um meio de comunicação que traz grande acesso à informação e é entendida pelos usuários como um espaço de pesquisa de informação, de encontro e de compartilhamento.

Embora em um perío do relativamente curto, que inclui menos de duas décadas, o ecossistema publicitário digital já passou por algumas fases que vão desde a inserção dos primeiros banners com conteúdos estáticos, reproduzidos da mídia impressa, até aqueles com formatos em movimento, dinâmicos e interativos. $\mathrm{E}$, ao longo desta trajetória, a busca pelas meIhores possibilidades e pelo bom atendimento ao usuário sempre esteve permeando a publicidade realizada na internet, proporcionando o encaixe dos dispositivos (formatos publicitários), dentro do dispositivo maior (internet).

A evolução das formas de comunicação entre empresas e consumidores faz parte de um processo que tem relação direta com a tecnologia, que insere possibilidades de transmissão de mensagens cada vez mais complexas e eficazes. É necessário que os responsáveis pela comunicação considerem sempre as ferramentas disponíveis no mercado já que as possibilidades existentes já possibilitam direcionar as mensagens de acordo com o público, e, quanto mais específica e avançada a tecnologia, mais provável a chance de alcançar os objetivos propostos e trazer retorno para os anunciantes.

Em suma, a publicidade é inconstante e vai seguir mudando. Isso acontece porque as pessoas que a fazem e a quem ela se destina, isto é, seu público-alvo, está em constante mudança. Aos publicitários cabe adaptarem-se e entenderem que hoje, mais do que antes, medição e monitoramento das atividades desenvolvidas é essencial, tanto quanto a capacidade cria-

Rev.Cad.Comun. Santa Maria, v.21, n.2, art 6, p. 123 de 125, maio/ago.2017 
CADERNOS DE COMUNICAÇÃO

UNIVERSIDADE FEDERAL DE SANTA MARIA

tiva de surpreender e impactar os usuários desse ecossistema.

\section{REFERÊNCIAS}

DUARTE, Marília. Métricas de mídia online. In: GOMES, Wilson; REIS, Lucas (Orgs.). Publicidade digital: formatos e tendências da nova fronteira publicitária. Salvador: P\&A Editora, 2011. p.65- 84.

FERNANDES, Breno. Do banner ao widget, passando pelo rich media: dimensão e interatividade como principais aspectos para anúncios na web. In: GOMES, Wilson; REIS, Lucas (Orgs.). Publicidade digital: formatos e tendências da nova fronteira publicitária. Salvador: P\&A Editora, 2011. p.47-63.

MCMILLAN, Sally J., Exploring models of interactivity from multiple research traditions: users, documents and systems". In Leah A. Lievrouw, Sonia Livingstone (org.), Handbook of New Media. Social Shaping and Consequences of ICTS, London, Sage, 2002. Disponível em: <http://sk.sagepub.com/reference/hdbk_newmedia/n12.xml> Acesso em 29 jun. 2016.

PINHO, José Benedito. Comunicação em marketing: princípios da comunicação mercadológica. Campinas, SP: Papirus, 2001.

SCOLARI, Carlos A. Ecología mediática, evolución e interfaces. Hipermediaciones, abr. 2012. Disponível em: <http://hipermediaciones.com/2012/04/23/ecologia-mediatica-evolucion-e-interfaces/>. 11 out. 2012.

SEBASTIÃO, Sónia. Formatos da publicidade digital: sistematização e desambiguação. In: Revista Comunicação e Sociedade. vol. 19, 2011, pp. 13-24. Disponível em: <http:// www.lasics.uminho.pt/ojs/index.php/comsoc/article/view/894> Acesso em: 4 maio 2014.

Rev.Cad.Comun. Santa Maria, v.21, n.2, art 6, p. 124 de 125, maio/ago.2017 


\section{Eugenia Mariano da Rocha Barichello}

Doutora e Mestre em Comunicação pela Universidade Federal do Rio de Janeiro. Professora Titular da Universidade Federal de Santa Maria.

E-mail: eugeniabarichello@gmail.com

\section{Taís Steffenello Ghisleni}

Doutora em Comunicação pela Universidade Federal de Santa Maria. Professora no Curso de Publicidade e Propaganda do Centro Universitário Franciscano.

E-mail: taisghisleni@yahoo.com.br

A tese que originou este artigo foi orientada pela Dra. Eugenia Mariano da Rocha Barichello e defendida em 25/11/2016, na linha Mídia e Estratégias Comunicacionais do Programa de Pós-graduação em Comunicação pertencente à UFSM.

RECEBIDO EM: 28/01/2017

ACEITO EM: 27/03/2017 